\title{
Reducing Operational Fuel Costs of Airlines: A Model for Monitoring and Managing Fuel Consumption Using Unified Modeling Language
}

\author{
Savaş S. Ateş ${ }^{1}$, Haşim Kafalı ${ }^{*}$, Gökhan C. Kılıçoğlu ${ }^{1}$ \\ ${ }^{1}$ Anadolu University, Faculty of Aeronautics and Astronautics, Eskişehir, \\ ssates@anadolu.edu.tr; gckilicoglu@anadolu.edu.tr \\ ${ }^{2}$ Muğla Sıtkı Koçman University, Dalaman School of Civil Aviation, Muğla, \\ hasimkafali@mu.edu.tr \\ *Corresponding author
}

Received: 28 December 2017

Accepted: 8 March 2018

DOI: $10.18466 /$ cbayarfbe. 372436

\begin{abstract}
The economical balance of airline operators is fragile because of their presence in a highly competitive environment and high fixed and variable costs. The ability of airline companies to cope with high competition by providing economic equilibrium depends on operational efficiency. One of the major operational costs of airlines is fuel. Some of the reasons leading airlines to fuel economy are fuel prices and environmental factors. Airline operators have to control fuel consumption without falling outside the scope of operational procedures and safety rules. For this reason, airline operators are constantly looking for ways to reduce fuel costs, which is a key component of service delivery costs. At the beginning of this quest is to increase the effectiveness of the operational processes. In the first part of the study, the reasons leading airlines to fuel economy were examined. The second section, lists the ways in which airlines save fuel. In the last part, a fuel management model proposal was made using a unified model language to develop a computer software. At the end of the research, developed unified model will provide decision support for monitoring and managing fuel consumption and costs.
\end{abstract}

Keywords: Fuel Economy in Aviation, Aircraft Operation, UML modelling, Decision Support System, Airline

\section{Introduction}

In airline business, the very basic factors determining the competitive advantage, in the simplest form, are price, quality and cost efficiency. Airlines do not have many options to directly affect the prices in highly competitive airline market because price is mostly determined by the market dynamics. Therefore, airlines primarily focus on their costs. They have to gain a competitive advantage by keeping costs under control, especially in the case of internal elements of costs like operational procedures. Airlines that are under pressure to manage their costs due to internal factors are also under pressure by external factors.

External factors such as fluctuations in fuel prices with crises and market equilibrium, restriction of environmental emissions by international organizations, and market competition considerably affect airline fuel costs. Airline management, in search of measures against all these fundamental external factors, first tries to find out the problem and then investigates solution methods. Historically, fluctuations in fuel prices are the most important factor affecting the cost of fuel. Also, United Nations and other organizations made mandatory global warming restrictions and emission restrictions with the decisions they made in the 2000s. This has emerged as another factor that must be addressed by the management for fuel efficiency. Management needs to focus on issues such as technological investments and developments, operational improvements, alternative fuel use to reduce fuel consumption. Fuel consumption will provide airlines with economic advantages. It is also environmentally important.

In the first part of the study, the reasons leading airlines to fuel economy were investigated by a literature review. In the second part of the study, operational fuel saving methods in airlines were listed. In the last part of the study, a fuel monitoring management model was developed using a Unified Modeling Language (UML) for the development of a computer software. 


\section{Literature Review}

Because fuel cost is one of the most important costs, there are direct effects of it on profit and competition, which are the main objectives of any enterprise. The reasons leading airlines to fuel economy can be listed as follows:

Fuel Prices: The ups and downs in oil prices affect the airlines very much. In the event of an increase in fuel prices, airlines will have to reflect this increase mostly in their prices. In this case, the demand for the airline will decrease. Declining demand will lean to competitors who do not raise prices. This will be reflected in revenue losses, decline in sales and market losses [1]. That is why airline operators are eager to save fuel. The two biggest costs in air transport are fuel and labor. According to the information given by The International Air Transport Association (IATA), the greatest cost for large airlines in 2008 is the fuel cost with $32.3 \%$. IATA is a trade association of the world's airlines, and also it supports airline activity and helps formulate industry policy and standards. While the cost of a barrel of jet fuel in 2001 was around US $\$ 34.7$, this cost was $13.6 \%$ on average; but, in 2008, when the cost of jet fuel increased to US $\$ 126$ per barrel of jet fuel, this cost increased by more than 2 times and became $32.3 \%$. This resulted in an additional cost of US $\$ 34.5$ billion in the sector $[1,2]$.

Environmental Factors: Airlines must adhere to the regulations of the country where they are located. They also have to comply with the regulations of the countries they fly to and the regulations of the states whose airspace they use. States supervise and regulate safety and maintenance requirements in following the market competition and intervening when necessary. They also supervise and regulate issues of entering and withdrawing from the market, pricing, environmental regulations, and issues about safety [2]. As the consequences of global warming will concern the whole world, international cooperation is necessary to solve the problem. For this reason, international organizations and governments have made various arrangements and agreements on this issue. The International Civil Aviation Organization (ICAO) is a specialized agency of the United Nations. It arranges the principles and techniques of international air navigation and fosters the planning and development of international air transport to ensure safe and orderly growth. The ICAO states that with technological advancements, air vehicles consume $80 \%$ less fuel than in 1960 and this ratio drops by $1-2 \%$ annually, but the air traffic increases by $4-5 \%$ per year [3]. The ICAO developed methods, which it calls basket measures, including certification standards for air vehicle production technology (composite material, high engine performance), operational improvements (such as ground handling/operations, air traffic control), renewable energy sources, emission trading, and emission tax [3]. At the 2010 ICAO meeting, 2 goals for aviation were identified: $2 \%$ fuel saving per year up to 2020 and neutralization of carbon value as specified in Paris agreement for 2021-2050 [4]. A 3\% fuel saving target for each year was set for IATA member airlines. Airline fuel consumption is expected to decrease by $25 \%$ from 2005 to 2020 [5]. A flight cycle consisting of taxi, departure, climb, approach and taxi phases, which ICAO calls LTO (landing and take-off cycle), was defined, and standards were set for measuring emissions for each section of the cycle [6].

Management Factor: $A$ management's decisions can be classified as strategic, planning and operational [2]. The increase in the number of airlines is pushing airway management to lower costs, increase revenue, and generate a steady profit in the market growth and intense competition environment. Major airlines pursue fuelhedging to lower fuel costs, using more economical newgeneration planes and jet engines in the event of fuel price instability. The average fuel consumption of new planes is reduced by $45 \%$ compared to old planes. The annual average decrease in fuel consumption is calculated as $1.4 \%$ [7]. Southwest Airlines announced that it reduced all operation costs in the first quarter of 2015 by $8 \%$, which corresponds to US $\$ 3.6$ billion. The $8 \%$ decline in total operation costs is the largest source of fuel costs, down $\$ 877$ million at a scale of $33 \%$. The biggest factor in this decline is the fuel contract made by Southtwest Airlines [8]. In 2014, Delta Airlines paid $\$ 2.87$ per gallon for fuel and American Airlines paid \$2.91. In 2015, Delta Airlines paid \$2.23 per gallon because it signed a fuel contract. American Airlines, which did not sign a contract, paid \$1.72. Delta Airlines suffered a loss of $\$ 336$ million in the last three months of the year, because fuel prices fell, and American airlines paid $41 \%$ less for fuel than the previous year [9]. Delta Airlines has announced that they have lost $\$ 4$ billion over the last 8 years due to fuel contracts.

Competition: Airlines are not independent in the sector. There are many institutions and businesses that play a role in the sector. Therefore, airlines also work together with these institutions. Primary ones of these institutions and enterprises are states, airports, customers, other airlines, alliances, suppliers, trade unions, and competitors [10]. A study was carried out only on operational fuel efficiency [11] for 15 different traditional regional and low-cost airlines in the US in 2010. When the fuel consumed per mile per passenger was calculated, there was a difference of about $25 \%$ between the top three best performing airlines and the last three airlines that appeared to be inefficient. Generally, deep-rooted and large airlines have less efficient fuel use than low-cost and relatively smaller competitors. In the same study, when the number of departures is compared to the passenger income per mile, a different result emerges. The number of departures of an airline, which ranks 11th in terms of passenger revenue per fuel/mile, rises to the first place in the table when a comparison is made between passenger income per mile. The airline that appears to be the most productive, Southwest 
Airlines, had a number of departures of more than 1 billion in 2010, and Virgin America, which appears to be inefficient, made about 36,000 departures [12-14]. These are because the cost is falling due to the aforementioned intensity of the economy. However, Delta Airlines ranking the second in the number of departures (730 thousand) and American Airlines following Delta (545 thousand) display an inefficient picture also at this cost evaluation. US Airways looks more efficient with over 400,000 departures $[1,15,16]$.

\subsection{Operational Fuel Saving Methods in Airlines}

Fuel in air transport is the most volatile and important operation cost. Managing this situation requires a great deal of effort. Fuel consumption directly affects operational costs, and therefore, cargo and passenger demand through prices. Airlines are aware of the consequences of inefficient fuel consumption, which are the increase in prices and market loss. They are more eager than ever to be more efficient at fuel costs. From operational point of view, the stages from engine start, taxi, takeoff, straight flight, approach, landing, taxi and engine stop are a cycle in which a plane consumes fuel during operation. The fuel consumed during these stages can be optimized with an appropriate operation planning and strategy. This optimization is done to provide operational efficiency both in the air and on the ground. Given the actual aircraft performance, operational constraints, safety, efficiency, operational planning and procedures, fuel economy can be achieved in theory at the levels possible. Some of the operational steps that airlines use to provide this efficiency can be listed as follows $[7,17,18]$ :

- Flight network regulations

- Aircraft Center of Gravity Optimization

- Fuel Planning

- Tankering

- Ground Operation Optimization

- Fleet Planning

- Air Traffic and Flight Plan Optimization

- Optimization of Taxiing Procedures

- Aircraft Performance Optimization

\section{Purpose and Significance}

Airline management requires making highly complex decisions due to characteristics of the sector. In literature review section of the study, it was explained why airlines have to save fuel and how improvements in operational procedures help airlines to be more fuel efficient. The purpose of this research is to suggest a fuel management model for operationally monitoring and regulating fuel consumption in all steps of the operation for airline operators. UML (Unified Modelling Language) was used as the modelling method. UML is a modelling language used to visually explain software components and the relations between them. It is also used to make complex processes, business procedures and systems simple and straightforward with the help of visual instruments such as diagrams

\section{Proposal for A Model}

After determining the operational factors affecting fuel consumption in the literature review, diagrams were created using UML, which is used in the design of computer software, to create an object-based fuel management model. A modeling was done to create the basis of the system and to determine which objects would form the system. No software or user interface was created in this model, so no coding was done.

\subsection{Database}

The most important factor for the model is the method of collecting and storing data. Adequacy and accuracy of the data entered is the key factor to impact the general and specific efficiency of the system output. The data should be accessible, usable and accurate all the time. The model or the system, first of all, should have databases to maintain and manage all data. Functionality increases if the data flow to databases are organized as Manual and Automatic depending on the source of data. The purpose of using different databases for manual and automatic entries is to provide the accuracy of data supplied from different sources. Moreover, maintenance is simplified in the possibility of unreliable or missing data. The system should also have a backup database for each database to keep the data safe and to be able to retrieve the data when needed (Figure 1).

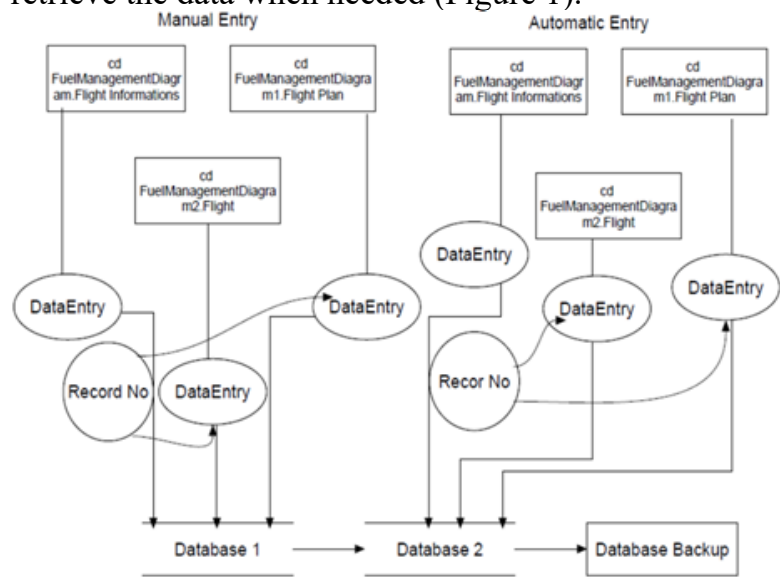

Figure 1. Database

\subsection{Flight Plan Classes of the Model}

The amount of fuel consumed by an aircraft varies based on flight time, aircraft performance, weight, weather conditions, air traffic and ground traffic (such as delays and so forth). Detailed data have to be obtained in terms of above variables in order to be able to analyze how much fuel is burned, during which stage of the flight fuel is burned, and what the fuel efficiency of the flight is during the operation. The first stage of a flight is the planning of the flight. Thus, monitoring and managing fuel starts at this stage. According to Diagram 1, given that the flight plan is a class of the model, sub-classes - 
Celal Bayar University Journal of Science

Volume 14, Issue 1, p 105-111

forming that class and having relationships within themselves - were formed to record all stages and data of the planned fuel.

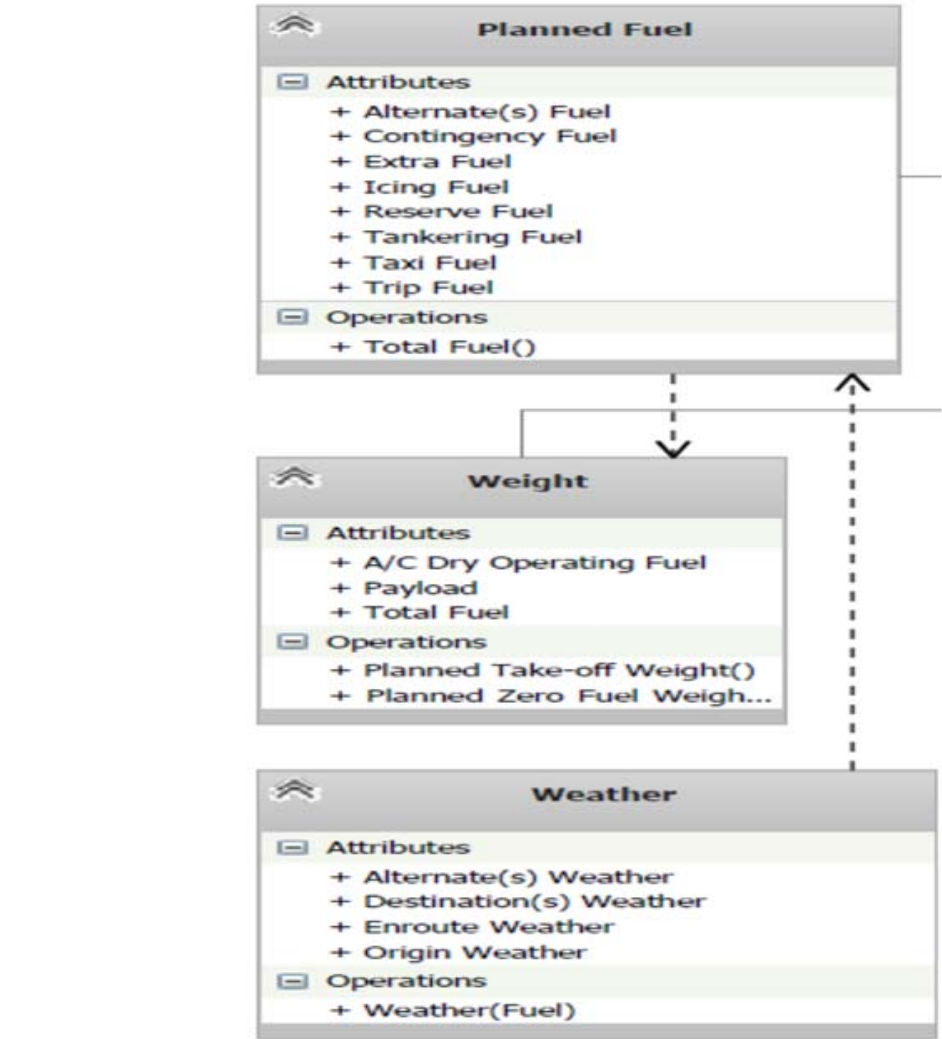

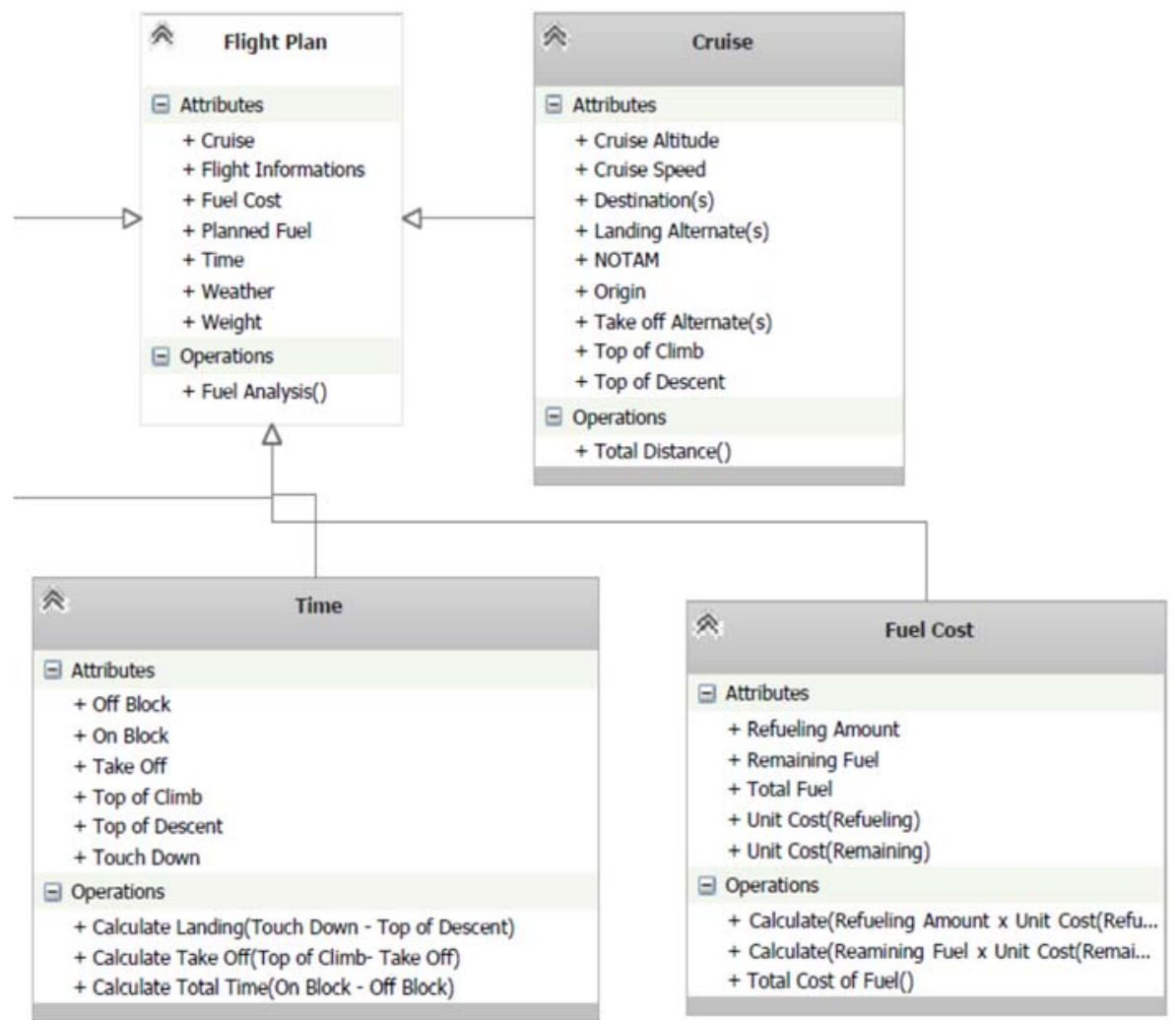

Diagram 1. Flight Plan Diagram 


\subsection{Real Flight Classes of the Model}

The reason for creating a real-flight class and its subclasses is that planning a flight may be very close to real conditions, but real flight conditions may be different due to the influence of many variables and performance issues. This difference can be trivial or significant. Because of this difference, receiving data from the real flight is very important. Therefore, this class - composed of information gathered from aircraft systems and flight crew during and after flight depending on the ability of the airplane, and from ground crew - provides realistic data for fuel analysis. This class has the real information for the flight and the nature of its data is retrospective and irremediable. Therefore, the analysis of the real data gives realistic results. This feature, which restricts correction, has the potential to be more efficient for the next flight when adequate data is available (Diagram 2).

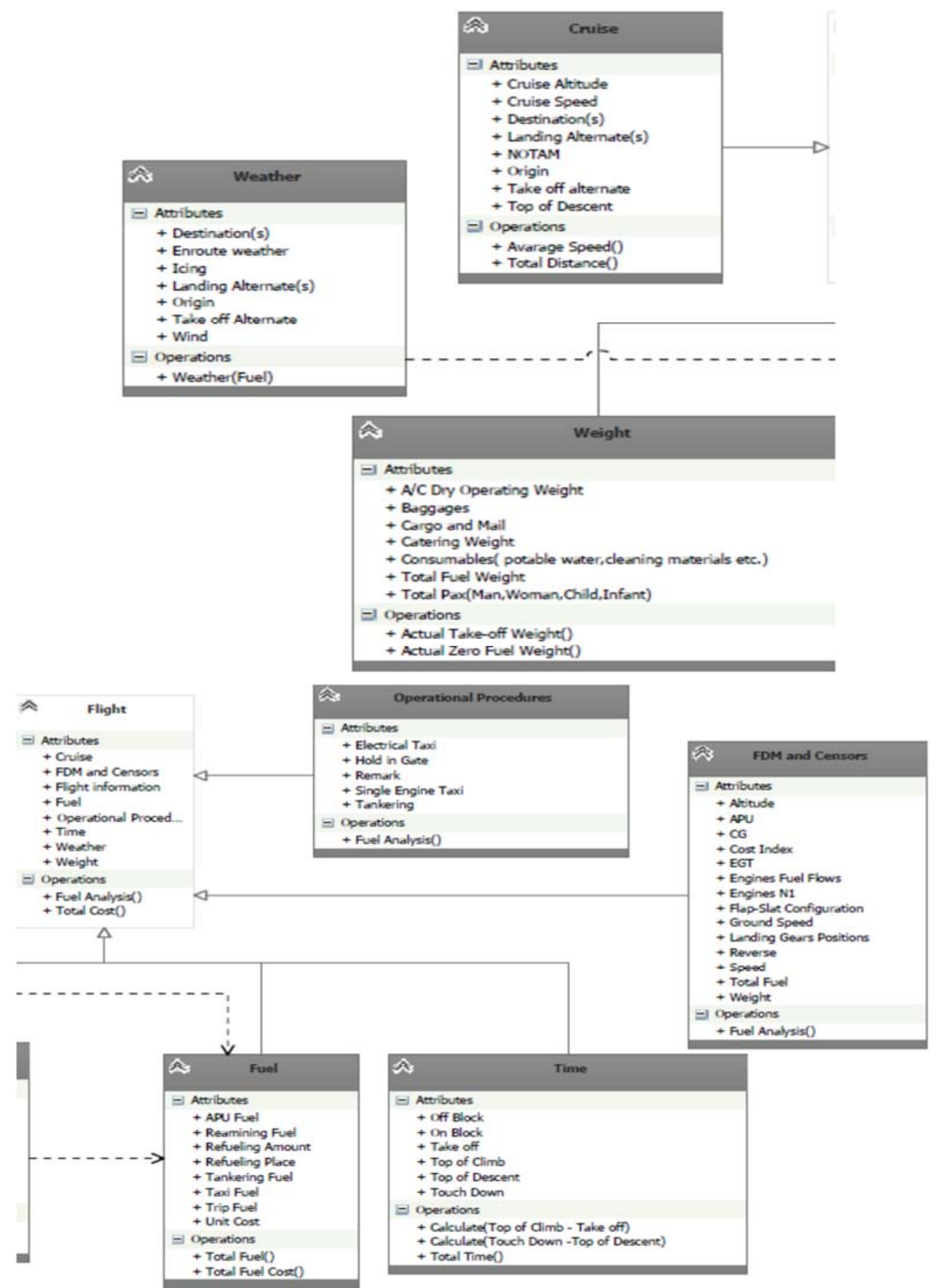

Diagram 2. Flight Diagram 


\subsection{Analysis Class of the Model}

The model's analysis class includes the process of creating a general analysis by evaluating outputs from the flight plan and real flight classes together with technical defects and failures occurring or recorded in the aircraft. As seen in Diagram 3, it receives information from the maintenance class, real flight class and flight plan class and incorporates this information into the analysis process. It builds a general analysis plan and assigns this analysis to the record number from the required flight information class, which is unique and contains specified flight information. This model can be programmed to suit the preferences of the airline management to display the results visually, written or statistically. The flight information class is made up of specific information about that flight. The registration number to be created will therefore only belong to that flight.
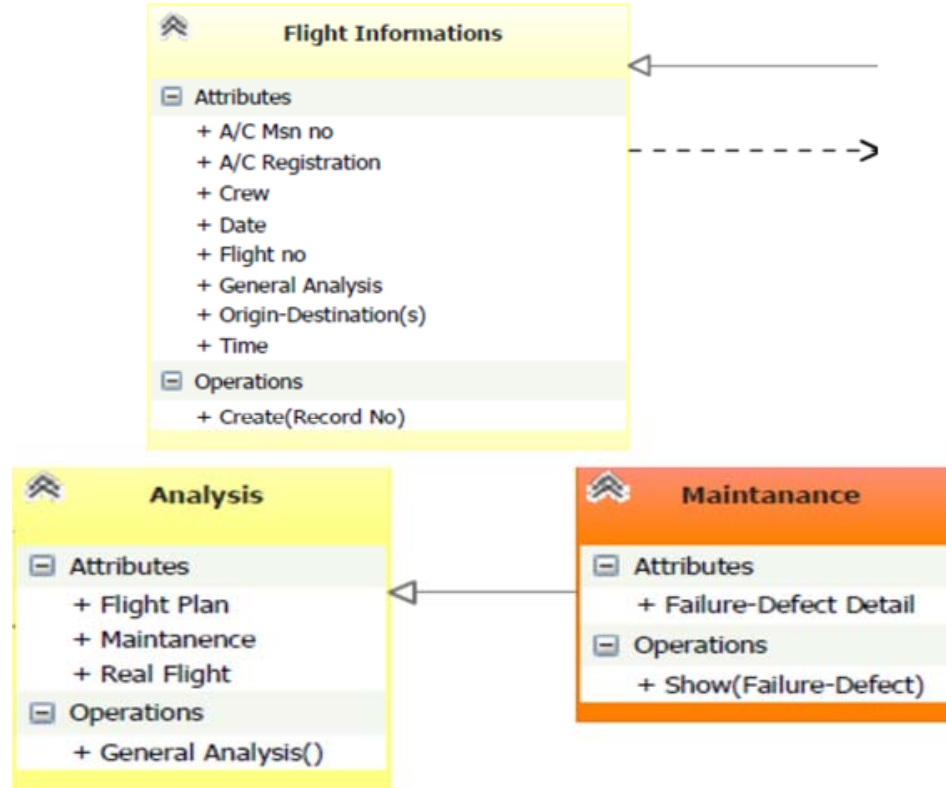

Diagram 3. Analysis Diagram

\subsection{Analysis Control}

Figure 2 shows the control flow of the model. This control process is necessary to check the possibility that the analyses were done using incorrect or inconsistent data. The analyzes made in the sub-classes that make up the analysis class and the data entered must be consistent within themselves. This flow gives the opportunity to control the process and take correction actions against inconsistent or irrational analyses.

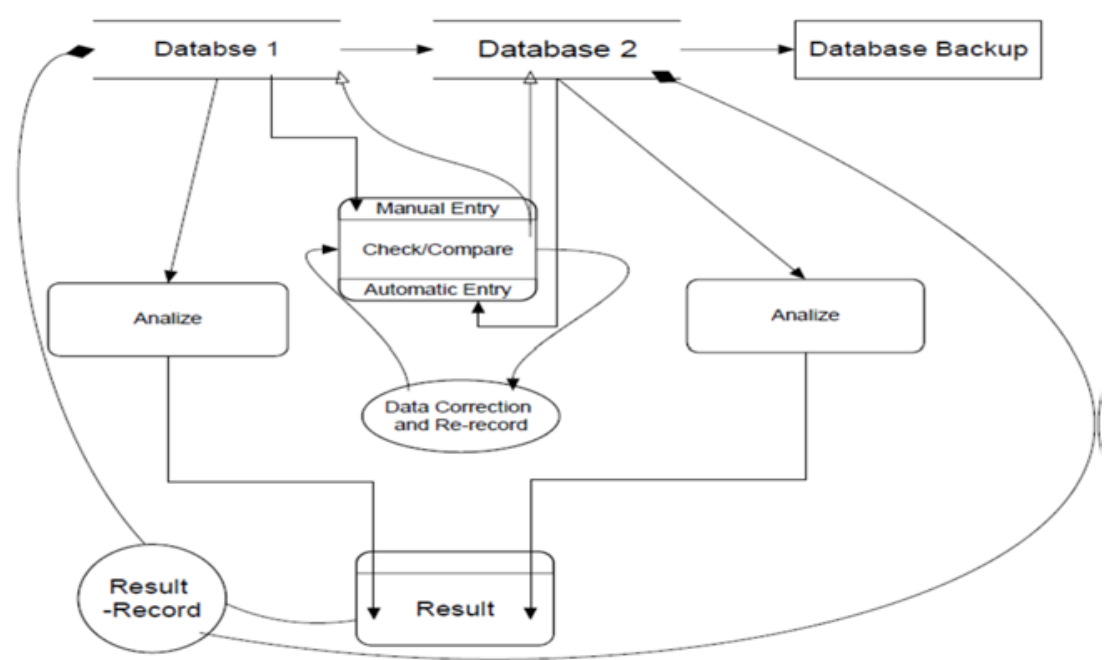

Figure 2. Analysis Control 
The data entered can be manual only, automatic only, and both automatic and manual. It is therefore necessary to check that there are no large differences in the data entered and that they are within the predetermined limits. If there is an error, the data is comparatively checked again, corrected and re-recorded so that the program has a more realistic database for analysis. The analysis done with the corrected data is recorded one last time and saved finally as the resultant output into the databases of the system.

\section{Conclusion}

It is a challenging activity for air transport and airline management to monitor, control and reduce fuel consumption and costs because of the complexity and uncertainty of operations.

However, it improves the effectiveness of management and the efficiency of the airline by providing analyses for responding to questions such as establishing a monitoring and management system involving operational processes, remedying the flawed characteristics in operations, how much fuel savings can be achieved at which stages. By means of the actual consumption values and analyzes of all steps provided by the system, a more detailed and more transparent information environment will be created in terms of fuel. The system will also enable conducting performance analyses of basic elements such as sector, aircraft, team, location and time, by carrying out comparisons within itself. The yield to be obtained from the system will be directly proportional to the quality and quantity of the data entered into the system.

In order to establish the fuel consumption profile of an airline, a certain time period and the fuel data of this period specified by the airline are required. Because the data and queries to be used to measure fuel efficiency will not be uniform, it is necessary to determine measurement techniques in a few different ways and transfer them to the system.

The system - and the desired outcomes - can be diversified by adding new elements to the system without changing its basis, depending on the changes made on operations over time or according to airline requests. Issues such as analyses on system usage and maintenance checks should also be tracked.

\section{Acknowledgments}

This study was supported as part of project 1705E158 accepted by the Commission on Scientific Research Projects, Anadolu University.

\section{References}

1. Koopmans, $C$, Lieshout, $R$, Airline Cost Changes: To what extent are they passed through to the passaneger?, Journal of AirTransport Management, 2016, 53, 1-11.

2. Abdelghany, A, Abdelghany, K, Modeling Applications in the Airline Industry, Routledge: New York, 2016.

3. ICAO, Enviromental Report, ICAO, 2016.

4. ICAO, Enviromental Report, ICAO, 2007.

5. IATA, Climate Change Fact Sheet, IATA, 2016.

6. Dickson, N, Local Air Quality and ICAO Engine Emission Standarts. In Action Plan pn Emmission, Reduction, Kenya, 2014.

7. Lim, S.H, Hong, Y, Fuel hedging and airline operating costs, Journal of Air Transport Management, 2014, 36, 33-40.

8. Southwest's fuel gamble: Hedges keeps fares in check,abcnews.go.com, http://abcnews.go.com/Travel/ story? $\mathrm{id}=5918252 \&$ page $=1,2017$ (accessed 20.05.2017).

9. Southwest Airlines and Cheap Oil: The Perfect Combination?,www.investopedia.com,http://www.investopedia.c om/articles/markets/072715/southwest-airlines-and-cheap-oilperfect-combination.asp, 2015 (accessed 21.05.2017).

10. Cento, $A$, The Airline Industry-Challenges in the 21 st Century, Heidelberg, 2009.

11. Zou, B, Elke, M, Hansen, M, Kafle, N, Evaluating Air Carrier Fuel Efficiency in the US Airline Industry, Transportation Research Part A:Policy and Practice, 2014, 59, 306-330.

12. Yalçın Erik, N, Koşaroğlu, Ş.M., Tarihsel Süreç Boyunca Değişen Petrol Fiyatları, C.Ü. Iktisadi ve İdari Bilimler Dergisi, 2016, 17(2), 119-143.

13. ATAG, Aviation Benefits Beyond Borders, 2016.

14. Delbari, S.A., Ng, I.S., Aziz, Y.A., Ho, J.A., An Investigation of Key Competitiveness Indicators and Drivers F Full Service Airlines Using Delphi and AHP Techniques, Journal of Air Transport Management, 2016, 52, 23-34.

15. Özmen, M, Using Pass-Through of Fuel Prices as Aproxy for Taxation Responses in the Aviation Industry, Gars Junior Researches, 2009, 5-7.

16. Kristjanpoller, W. D., and Concha, D., Impact of Fuel Price Fluctuations on Airline Stock Returns, Applied Energy, 2016, 178, 496-504.

17. Brueckner, J. K., and Abreu, C., Airline Fuel Usage and Carbon Emissions: Determining Factors, Journal of AirTransport Management, 2017,62,10-17.

18. Ryerson, m. S., and Kim, H., The Impact of Airline Mergers and Hub Reorganization on Aviation Fuel Consumption, Journal of Cleaner Production, 2014, 85, 395-407. 